\title{
A multifunctional urea co-crystal with combined ureolysis and nitrification inhibiting capabilities for enhanced nitrogen management
}

\author{
SUPPLEMENTARY INFORMATION
}

Luca Mazzei,,$^{a, d}$ Valquiria Broll, ${ }^{a, d}$ Lucia Casali, ${ }^{b, d}$ Manoj Silva,$^{c}$ Dario Braga, ${ }^{b}$ Fabrizia Grepioni,${ }^{b *}$ Jonas Baltrusaitis, ${ }^{* *}$, Stefano Ciurli**

${ }^{a}$ Laboratory of Bioinorganic Chemistry, Department of Pharmacy and Biotechnology, University of Bologna, Viale Giuseppe Fanin 40, 40127 Bologna, Italy

b Dipartimento di Chimica “G. Ciamician”, University of Bologna, Via Selmi, 2 - 40126 Bologna - Italy

${ }^{\mathrm{c}}$ Department of Chemical and Biomolecular Engineering, Lehigh University, 111 Research drive, Bethlehem, PA 18015, USA

d These three authors contributed equally to the work

Corresponding authors:

Fabrizia Grepioni: fabrizia.grepioni@unibo.it

Jonas Baltruisaitis: job314@1ehigh.edu

Stefano Ciurli: $\underline{\text { stefano.ciurli@unibo.it }}$ 


\section{Table 1-SI}

Crystallographic data and details of measurements for ZnTU.

\begin{tabular}{|c|c|}
\hline & ZnTU \\
\hline Chemical formula & $\mathrm{C}_{2} \mathrm{H}_{8} \mathrm{Cl}_{2} \mathrm{~N}_{4} \mathrm{OSZn}$ \\
\hline $\mathrm{M}_{\mathrm{r}}, \mathrm{g} \mathrm{mol}^{-1}$ & 272.47 \\
\hline $\mathrm{T} / \mathrm{K}$ & $293(2)$ \\
\hline Morphology, colour & Block, colourless \\
\hline Crystal system & Monoclinic \\
\hline Space group & $\mathrm{P} 2{ }_{1} / \mathrm{c}$ \\
\hline $\mathrm{a} / \AA$ & $11.7246(10)$ \\
\hline $\mathrm{b} / \AA$ & $6.8740(5)$ \\
\hline $\mathrm{c} / \AA$ & $11.9092(8)$ \\
\hline$\alpha /{ }^{\circ}$ & 90 \\
\hline$\beta / \circ$ & $97.013(7)$ \\
\hline$\gamma / \circ$ & 90 \\
\hline $\mathrm{V} / \AA^{3}$ & $952.6(1)$ \\
\hline $\mathrm{Z}$ & 4 \\
\hline $\mathrm{d} / \mathrm{mg} \mathrm{cm}^{-3}$ & 1.900 \\
\hline$\mu / \mathrm{mm}^{-1}$ & 3.312 \\
\hline $\begin{array}{l}\text { Reflections } \\
\text { collected/unique }\end{array}$ & $7014 / 2256$ \\
\hline $\mathrm{R}_{\text {int }}$ & 0.0382 \\
\hline Threshold expression & $>2 \sigma(\mathrm{I})$ \\
\hline $\mathrm{R}_{1}$ (obs) & 0.0543 \\
\hline $\mathrm{wR}_{2}$ (all) & 0.1465 \\
\hline
\end{tabular}


Figure 1-SI. DSC traces for (top to bottom) urea, thiourea, ZnU, ZnT, and ZnTU.
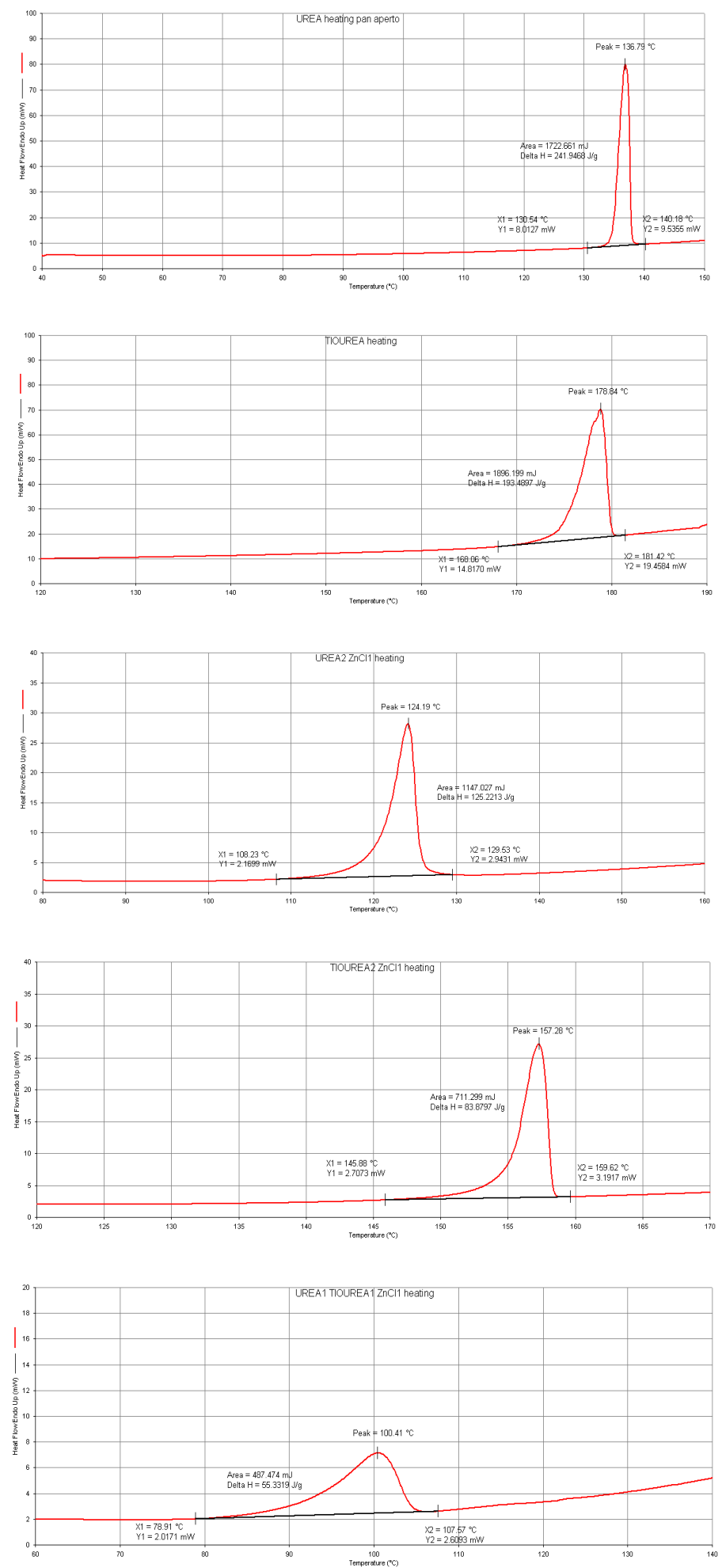
Figure 2-SI. TGA traces for (top to bottom) urea, thiourea, ZnU, ZnT, and ZnTU.
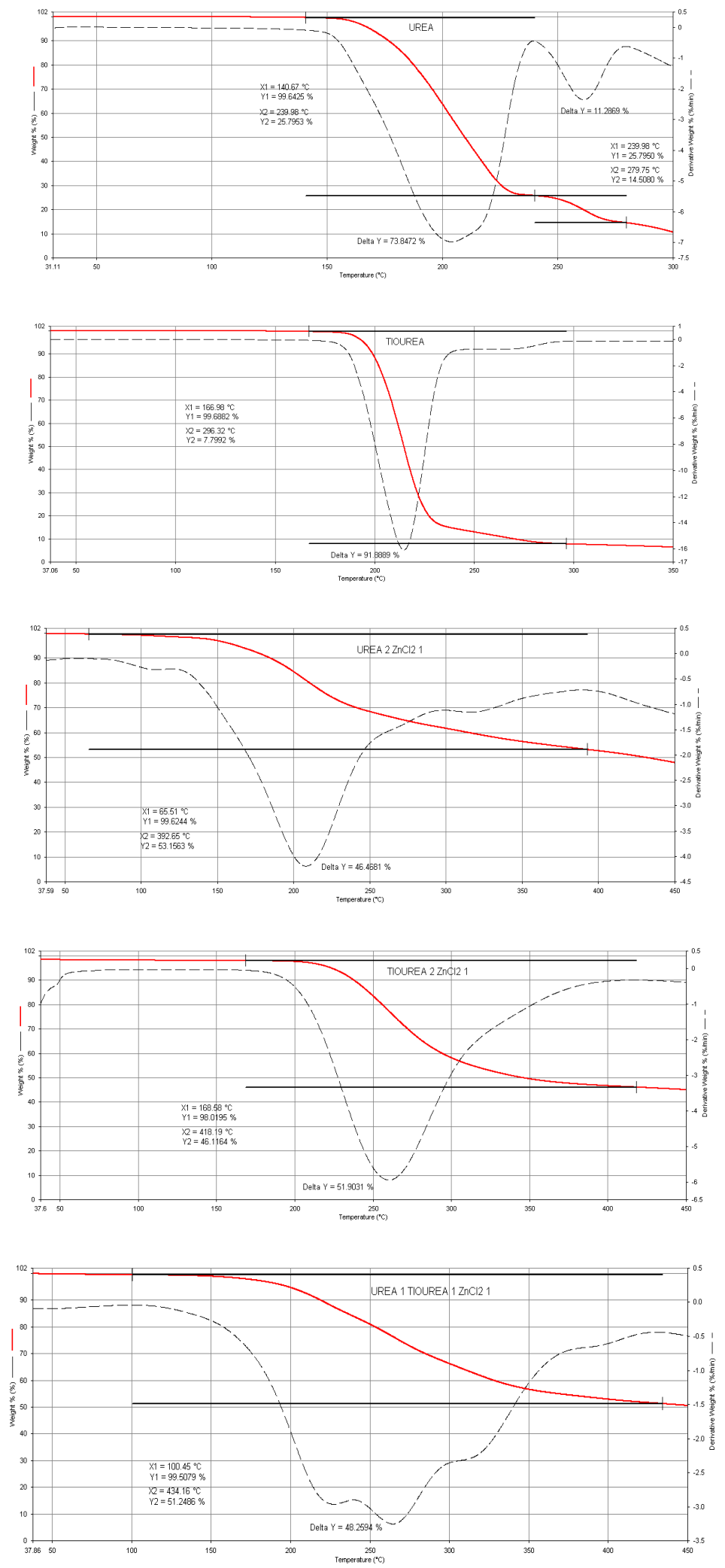


\section{Figure 3-SI}

Representative raw data diagram showing the amount of oxygen consumed over time during N. europaea reactions. The experimental conditions are described in the material and methods section.

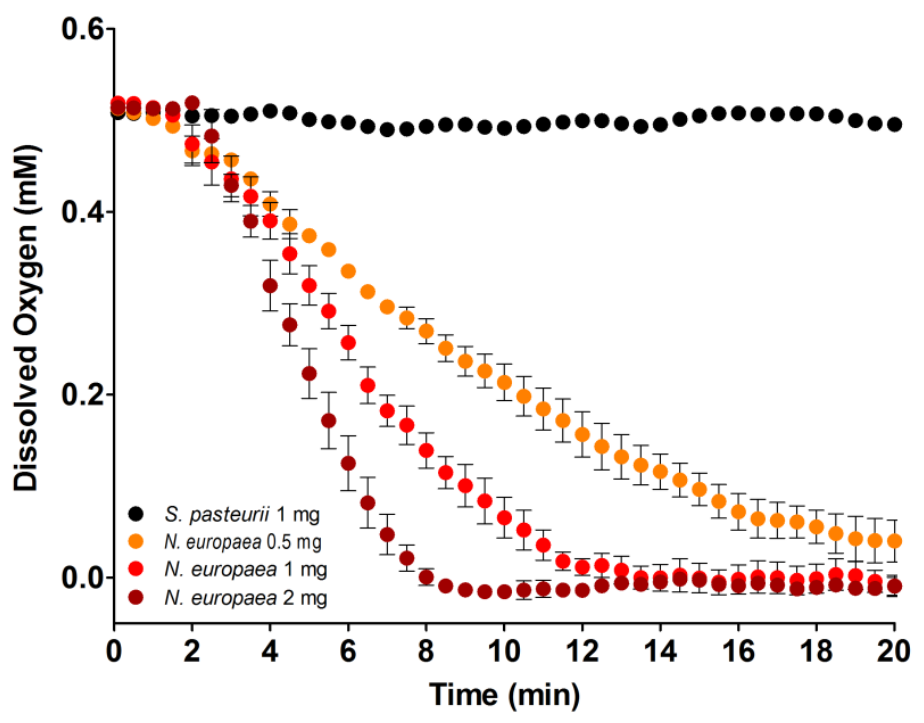


Figure 4-SI

X-ray powder pattern (black line) of the residual solid (2.82 g) obtained upon addition of $4.53 \mathrm{~g}$ of ZnTU (containing $1 \mathrm{~g}$ of urea) to $1 \mathrm{~mL}$ of water. It can be appreciated that the residual solid is a mixture of ZnTU (red line) and ZnT (blue line).

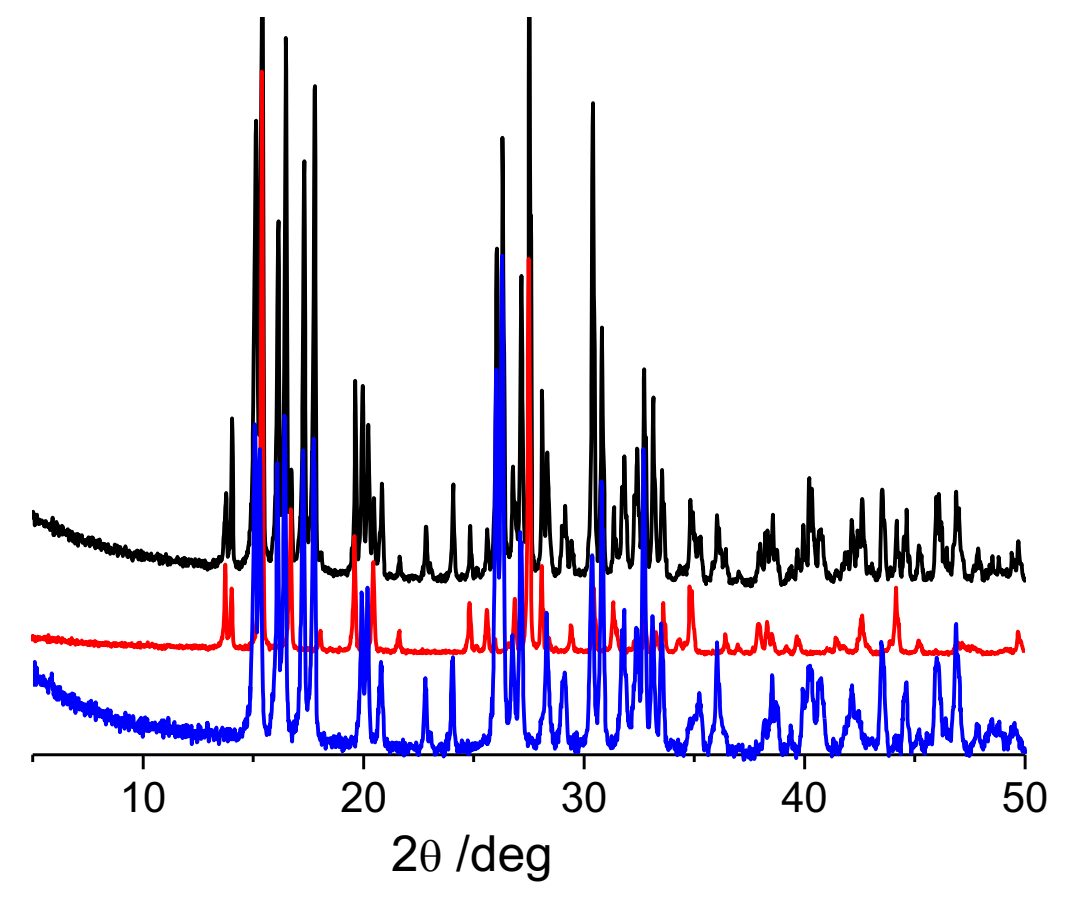




\section{Figure 5-SI}

Comparison of the experimental powder patterns measured on a freshly prepared sample (black line) of ZnTU and on the same sample stored for 6-months (red line) at ambient conditions in an open flask.

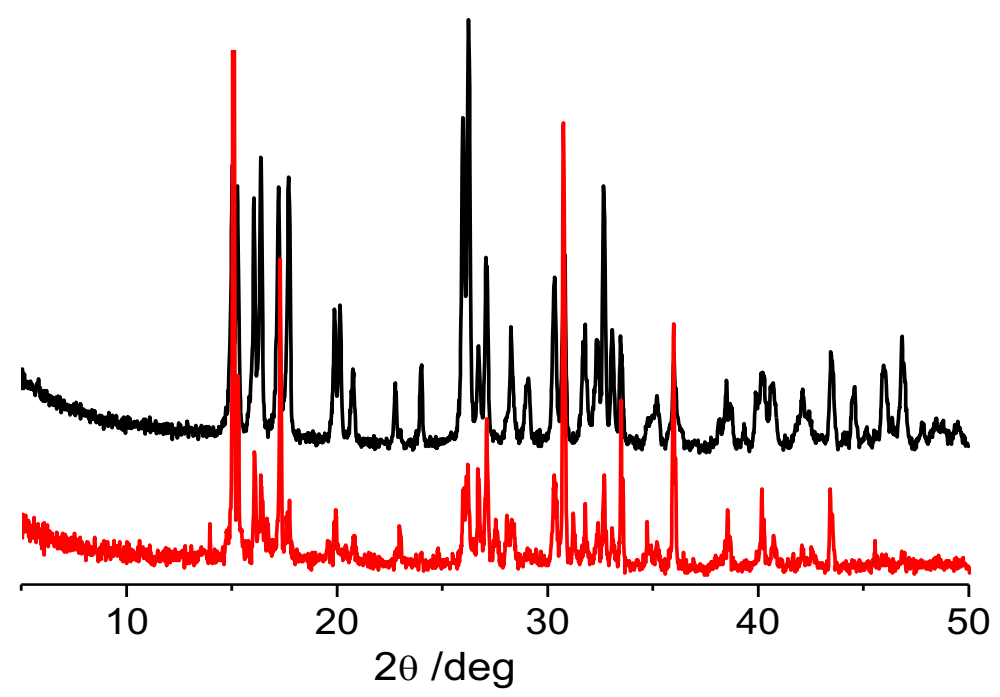


Figure 6-SI. $\mathrm{ZnTU}, \mathrm{ZnU}$ and $\mathrm{ZnT}$ as prepared $(\mathrm{t}=0)$ and after three days in a chamber at controlled humidity $(82 \% \mathrm{RH})$. It is evident that, while $\mathrm{ZnU}$ has absorbed water and turned into an aqueous solution, ZnTU shows the same behavior as ZnT (still a dry powder), suggesting that urea in ZnTU is stabilized with respect to urea in $\mathrm{ZnU}$.

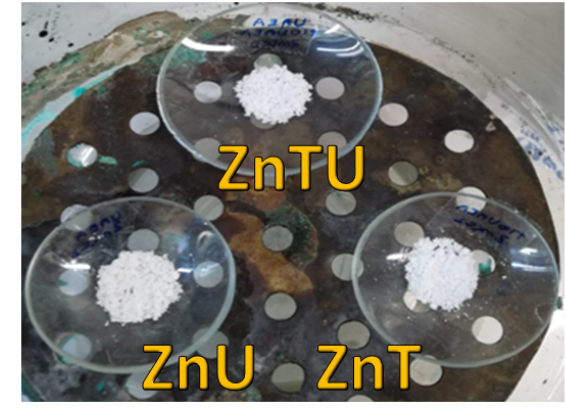

$t=0$

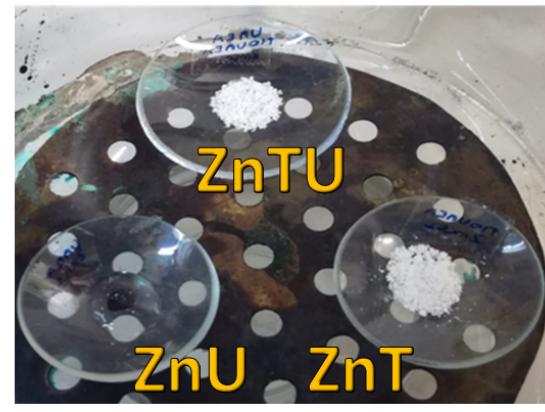

$t=3$ days 
Figure 7-SI. Adsorption/desorption branches of RH on urea, ZnU, thiourea, and ZnT
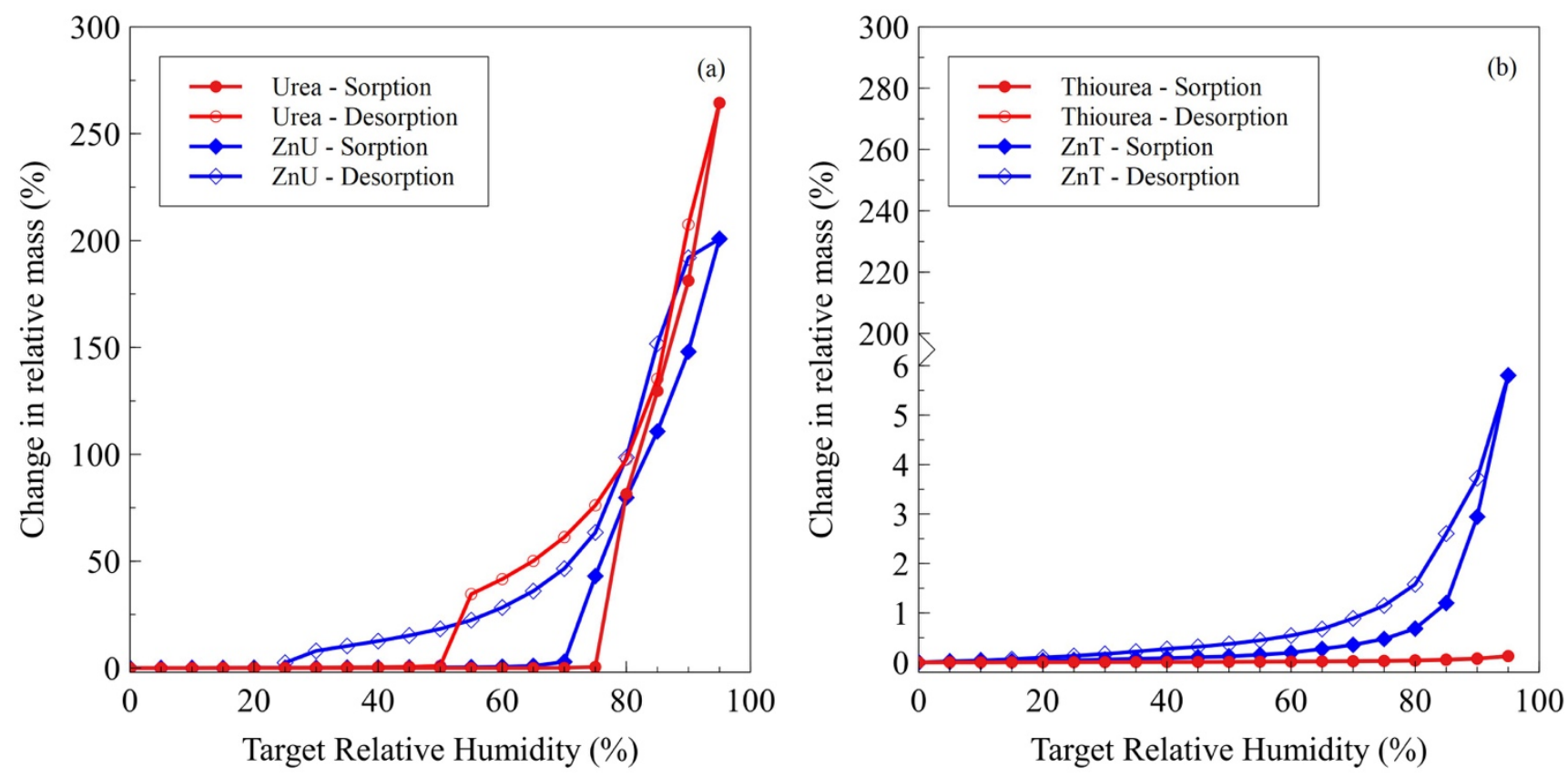